\title{
AUTOETNOGRAFIA NA PESQUISA EM EDUCAÇÃO HISTÓRICA UM DESAFIO AUTONARRADO
}

\author{
AUTOETHNOGRAPHY IN EDUCATIONAL RESEARCH HISTORY CHALLENGE \\ AUTONARRADO
}

Lisiane Sales Rodrigues ${ }^{1}$

Fernando Jaime González²

\begin{abstract}
RESUMO: Integrar a autoetnografia como metodologia da pesquisa, e a pesquisa em Educação História no campo do saber empírico e epistemológico, é o desafio que esse texto apresenta. Numa perspectiva de pesquisadora e sujeito inerida no contexto da pesquisa, trago aqui a abordagem que está sendo desenvolvida em minha dissertação de Mestrado em Educação nas Ciências, de maneira que os métodos se cruzam, através das análises do contexto do lugar onde está sendo desenvolvida a pesquisa, observações dos alunos, suas narrativas e minhas autonarrativas que carregam as reflexões sobre minha prática, o cotidiano escolar e as influências que incidem sobre os sujeitos.
\end{abstract}

Palavras chave: Autoetnografia. Educação Histórica. Aprendizagem Histórica.

\begin{abstract}
Integrating autoethnography as research methodology, and research in History Education in the field of epistemological and empirical knowledge, is the challenge that this text presents. From the perspective of researcher and subject inserted in the research context, I bring here the approach that is being developed in my dissertation for Master's Degree in Science Education, so that the methods cross each other, through the analyzes from the context of where research is being developed, from students observations, their narratives and my self-narratives that carry reflections on my practice, everyday school life and the influences that affects on the subjects.
\end{abstract}

Keywords: Autoethnography. History Education. Historical Learning.

\footnotetext{
${ }^{1}$ Graduação em História pela Universidade Regional Integrada do Alto Uruguai e das Missões URI Campus de Santiago (2011). Atua como professora do ensino médio nas disciplinas de História, Sociologia, Filosofia na Escola Estadual de Ensino Médio Professor Antonio Barella, no município de Novo Machado - RS. Mestranda bolsista FAPERGS/CAPES no Programa de Pós-graduação em Educação nas Ciências da Universidade Regional do Noroeste do Estado do Rio Grande do Sul UNIJUÍ

2 rofessor de Educación Física pelo Instituto del Profesorado en Educación Física (1990) Córdoba, Argentina, mestre em Ciência do Movimento Humano pela Universidade Federal de Santa Maria (1996), doutor na mesma área pela Universidade Federal de Rio Grande do Sul (2010). Desde 1998 é professor da Universidade Regional do Noroeste do Estado do Rio Grande do Sul onde trabalha nos cursos de Educação Física e no PPG em Educação nas Ciências. É professor colaborador do PPG em Desenvolvimento Humano e Tecnologia da UNESP Rio Claro.
} 


\section{Introdução}

Desenvolver a pesquisa no campo da Educação Histórica na escola onde pesquisador e sujeitos investigados se relacionam diretamente foi o desafio que me propus para a dissertação do Mestrado em Educação nas Ciências. Realizar a pesquisa de maneira que os alunos não percebessem que estão sendo investigados, foi o modo encontrado para que pudesse identificar a aprendizagem construída e o desenvolvimento da consciência histórica sem que eles pensassem em respostas prontas, ou a melhor resposta as atividades propostas. Portanto as metodologias da pesquisa e de sala de aula foram desenvolvidas considerando as disposições construídas por esses sujeitos, que trazem influências da família, da religião, do lugar, da escola e das comunidades onde perpassam e se constituem socialmente. Para fazer isso, pensando e vivendo o cotidiano escolar, trazendo as implicações desse meio, que o trabalho ora proposto está sendo realizado numa perspectiva autonarrada.

A intencionalidade de trabalhar a aprendizagem histórica nesse sentido parte da necessidade de compreender como essas influências marcam os sujeitos. Como professora de História na escola, há dois anos e meio, sinto-me inserida dessa forma na pesquisa, nos dois âmbitos pesquisador/sujeito. A opção pela autoetnografia veio durante as orientações, organização dos textos e observações que trago da escola. Oportunamente meu orientador e eu optamos por uma metodologia onde pudesse compreender as perspectivas e expectativas dos sujeitos em questão e minha investigação, de uma maneira subjetiva e autorreflexiva.

A leitura que proponho, parte da integração da autoetnografia, como metodologia da pesquisa e a pesquisa em Educação Histórica, como campo do saber empírico e epistemológico. O trabalho de pesquisa para minha dissertação colocou-me diante desse desafio, unir o ensino/aprendizagem em história, nas perspectivas da educação histórica, com as minhas experiências em sala de aula, na escola e na comunidade onde meus jovens alunos estão inseridos. Para Schmidt et al (2010, p. 11) "A investigação no domínio da educação histórica pressupõe que a aprendizagem da história seja considerada pelos jovens como significativa em termos pessoais", creio que para o professor e investigador essa 
significância deva estar construída e internalizada, para que sua atuação/investigação atinja seus objetivos, tanto educacionais quanto investigativos. Dessa forma a autoetnografia propõe a participação do pesquisador como sujeito inserido na própria pesquisa, mostrando a sua subjetividade e reações a cada dado construído no campo empírico.

\section{A autoetnografia}

Com esse intuito trago neste trabalho, as observações possíveis detectadas dentro de meu campo de pesquisa os sujeitos, a escola, o lugar, cada um com suas determinadas implicações, participações e influências, que acabam fazendo parte do cotidiano dos alunos, de meu olhar e minhas inquietações. A autoetnografia segundo Martha Montero-Seiburth (2006) estabelece um diálogo e identifica situações críticas confrontando mitos e distorções criadas por uma aparente homogeneidade.

Cada individuo representa la diversidad de un grupo en sí, por el lenguaje, forma de pensar, o forma de navegar una o muchas culturas. Sin embargo, operamos como si existiera en nuestras sociedades toda una realidad homogénea que ha sido aceptada como una normativa y al reconocer sólo estas perspectivas mayoritarias, dejamos fuera lo particular y especial de cada individuo. No podemos asumir que la normativa monocultural y monolítica es lo usual, lo común y lo que impera. (MONTEROSEIBURTH, 2006, p. 2)

Para Montero-Seiburth (2006, p. 3) a utilidade da autoetnografia é de que nos leva não só a autorreflexão, mas também nos faz compreender integralmente os sujeitos nos contextos onde eles operam. "Para esto la autoetnografía sirve para transformar las perspectivas mayoritarias y homogéneas que utilizamos y las enfoca hacia la comprensión e incorporación de la diversidad individual en la interacción que se crea dentro de la escuela y el aula". Este enfrentamento entre investigador, sujeitos e cultura dentro das interações, autorreflexões e reconhecimento de emoções permitem a 
reconstrução de posicionamentos e identidades que segundo a autora proporcionam novos conceitos de realidade.

Para Adrián Scribano e Angélica De Sena (2009) o posicionamento do investigador, em um trabalho etnográfico, apresenta três eixos que Ihe dão suporte e características na qualidade de tornar-se uma autoetnografia, inserindo-a como metodologia das investigações nas Ciências Sociais: o primeiro é a relação entre o conhecimento e as incertezas nas Ciências Sociais, dessa maneira a possibilidade de vinculação "entre sujeto que observa y campo de observación es el que se condensa alrededor de la relación entre patrones de explicación e indeterminación" (ibid., p. 3).

Essas incertezas nas relações são uma constante no trabalho empírico desenvolvido em sala de aula, o que me faz retomar ou reconstruir um novo caminho metodológico, dentro das concepções da aprendizagem histórica, a cada momento em que coloco a minha prática e a teoria lado a lado, a cada construção e análise de narrativas. O que os autores colocam, que a análise leva a mudança e consequentemente uma nova atitude, para poder aceitar que os problemas surgem com as próprias teorias e práticas de investigação (BOHMAN apud SCRIBANO; DE SENA, 2009), assim mostra que não se está simplesmente coletando dados, mas sim os construindo, e que o olhar como sujeito integrante do movimento é parte importante dessa construção, carregado de subjetividade e autorreflexão.

Es en este contexto como se puede entender que la mirada del sujeto implicado en la construcción de un campo objetual no solo no es un obstáculo para la comprensión, sino que es un recurso y lo una condición para efectuar dicha comprensión. (BOHMAN apud SCRIBANO; DE SENA, 2009, p. 3)

O segundo eixo coloca a participação dos sujeitos na construção de conhecimento e do social, o quanto os sujeitos se envolvem com essa construção e com sua formação social, e as influências sofridas, os fazem desenvolver disposições para crer ou para agir. Nesse caso os autores colocam que modelos metodológicos perfeccionistas mostram a necessidade de uma construção teórica que considere os valores e práticas desses indivíduos: 
Si tratamos de reconstruir ahora la arista de participación nos encontramos con la postulación de la necesidad de integrar los problemas que los sujetos investigados consideran importantes a la investigación, de darles voz en la tomada de decisión metodológica y de incluir en la investigación la pregunta. Acerca de quién sirve la misma? (SCRIBANO; DE SENA, 2009, p. 4)

Os valores morais, sociais e éticos, dos sujeitos, são colocados à prova no momento em que se propõem assuntos que envolvam religiosidade, compreendendo a força das comunidades evangélicas locais, crença ou política, de maneira que essas abordagens devem sempre ser avaliadas antes e depois das aulas, dessa maneira as reações e colocações dos alunos e as minhas, tomam sentidos mais subjetivos, direta ou indiretamente. Dessa maneira, meus valores também são colocados em questionamento, a forma como penso, atuo ou decido diante dessas situações, de que forma eu represento para os alunos aquilo que estudo e defendo, Rüsen (2010, p. 55) aponta as relações da consciência histórica com valores morais da seguinte forma:

\footnotetext{
Esses valores morais são geralmente princípios, guias de comportamento, ideias ou perspectivas-chave que sugerem o que deveria ser feito em uma situação determinada, em que existem várias opções. Tais valores funcionam como fonte de arbitragem nos conflitos e como objetivos que nos guiam ao atuar. [...] Nossas perspectivas se enquadram nessa ação sistematicamente, reconhecem a relação social dentro da qual vivemos e devem decidir o curso de ação a tomar. Elas expressam esta relação social como uma obrigação para nós, dirigimo-nos, assim até a essência de nossa subjetividade, recorrendo a nosso sentido de responsabilidade e nossa consciência.
}

O terceiro eixo que os autores destacam é entorno de uma reconstrução de significado e a imersão no mundo da vida. "Que se entiende como reconstrucción interpretativa del mondo de la vida, implica un tomar posición frente la pregunta del otro/Otro sobre como la sociedad se hace de una forma y no de otra en la diversidad" (SCRIBANO; DE SENA, 2009, p. 4). Essa forma dialética se apresenta dentro da aprendizagem histórica, no momento em que os alunos necessitam se narrar como sujeitos da aprendizagem, e a forma como realizo a análise de suas narrativas, refletindo sobre elas, percebendo suas marcas familiares, sociais ou religiosas, traçando a tipologia das narrativas e autorrefletindo minha prática para, a partir de então, perceber posicionamentos, permanecer com o percurso 
planejado ou tomar novas posições. Então "o poder explicativo da narração" tanto na aprendizagem histórica como na autoetnografia explicita "elementos básicos da situação não somente para quem está de fora, como também para mim mesmo" (RÜSEN, 2010, p. 56).

Para Scribano e De Sena (2009) esses três eixos das pesquisas em Ciências Sociais compõe e dão suporte a autoetnografia. Portanto, como colocam os autores, o "gesto autoetnográfico" me propõe aproveitar minhas experiências "afetivas e cognitivas" da vivência do cotidiano de meu campo empírico, o que demostra também a importância de identificar o lugar onde a escola se insere, seu papel social nesse lugar, os sujeitos da comunidade escolar direção, professores e alunos. Sempre pontuando o que se coloca como realidade, mas cuidando e observando, pois:

La realidad no se presenta de modo límpido para el investigador la capte. La práctica del conocer tal vez pueda pensarse como un momento de aventura e imaginación sociológica, en la que genera la participación de al menos dos polos: el sujeto y el objeto que construyen dicho conocimiento. En una estrategia cualitativa los participantes de la misma adoptan múltiples posiciones, que se delinean de una manera u otra como prácticas de comunicación sujeto-sujeto, tratando de develar las producciones simbólicas y materiales de los mismos y los procesos de estructuración social en las cuales están involucrados. (SCRIBANO; DE SENA, 2009, p. 5)

A autoetnografia como método de pesquisa qualitativa é uma forma de trabalhar com "informações privilegiadas". Conhecimento e ação se unem e apresentam "nuances" que um observador externo não reconheceria. Por isso como investigador tem-se o privilégio e a responsabilidade de ser sujeito e objeto (SCRIBANO e DE SENA, 2009). Marcadamente:

Ello permite la propia interacción con el objeto de estudio e implica la posibilidad de formular (se) preguntas y conocer pareceres. El investigador no es invocado, convocado o participado de un fenómeno determinado por sus "cualidades personales" sino por ser parte de una comunidad, de un colectivo o de un evento a observar. El investigador es un participante activo capaz de narrar la escena en la que trabaja, conoce y posee un distinguido acceso al campo de observación que comparte con otros sujetos. (SCRIBANO; DE SENA, 2009, p. 6) 
As percepções dessa diversidade que a convivência no ambiente escolar, me fez reconhecer e avaliar criticamente o cenário que me envolve. As análises construídas então permeiam o trabalho realizado com os alunos do primeiro ano do Ensino Médio Politécnico na disciplina de História. As influências e disposições construídas por esses sujeitos e por mim marcam nossas trajetórias de ensino e aprendizagem. Portanto apresento uma autorreflexão combinada com o estudo de campo, pois o processo de investigação, ao descrever o grupo, vincula um nível pessoal de introspecção, ao passo que, ao construir os dados envolve também minha formação e identidade como ser social e professora de História. Nesse sentido a autorreflexão dá um tom autobiográfico à narrativa investigativa conectando o pessoal com as experiências culturais. (MONTERO-SEIBURTH, 2006)

A aprendizagem histórica dos alunos, a inteiração com eles e demais sujeitos do cotidiano escolar e minha prática, formam as bases para a construção dos dados empíricos desse trabalho. Identificar a aprendizagem através de narrativas, algo tão subjetivo, necessitava a compreensão do todo, isso levou a investigação para além das narrativas dos alunos, atingindo assim a intencionalidade de suas construções. Para isso se fez necessário a utilização de um Diário de Campo, como um instrumento, onde minhas observações desse cenário estão expressas: descrição das aulas, conteúdos, atividades, reações dos alunos e minhas, nossos diálogos, as reuniões dos professores da área das Ciências Humanas, os Grupos de Trabalhos da escola, as formações e reuniões pedagógicas, assim como também tráz anotações sobre as conversas e reuniões com os pais desses alunos, onde em um contato mais direto, pode-se identificar algumas características particulares. A importância do Diário de Campo está especificamente em poder colocar as percepções e poder reavalia-las a todo o tempo.

Como Scribano e De Sena (2009, p. 6) colocam que não há uma receita certa, e que este tipo de investigação é como "ir ao bosque sem mapa", mas com objetivos e metas traçadas, e um percurso para alcança-los. Apontamentos sobre as aulas, reuniões com pais, professores, formações e acontecimentos marcantes do dia a dia da escola e que definem a identidade do lugar foram 
documentados e tomam corpo no Diário de Campo, me auxiliam a traçar o mapa para o meu "bosque".

\section{A educação histórica o campo epistemológico}

No âmbito da Educação Histórica, como campo epistemológico, um dos passos do processo investigativo é construir análise e conhecimento através da interpretação das narrativas produzidas pelos alunos, para isso se faz necessária à compreensão do lugar de onde esses sujeitos falam. O contexto social como um todo revela suas influências na voz e na escrita desses jovens, o que demonstra a importância da descrição desses aspectos para que possa compreender suas constituições sociais.

A Educação Histórica busca na Didática da História, como ciência do ensinoaprendizagem, o desenvolvimento da consciência histórica dos educandos. As investigações e as práticas voltadas a uma Didática da História mostram que, o desenvolvimento da consciência histórica a partir da aprendizagem específica, desestabiliza as formas tradicionais de ensino aprendizagem da História. Mais do que nunca, ela mostra aos seus sujeitos a História como agente de transformação. Schmidt (2009, p.32) trata como uma nova demanda cognitiva, que se impõe relacionada com uma "aprendizagem comprometida com a sociedade humana, com a preparação para o conhecimento, além do mero adestramento ao exercício do trabalho material", uma aprendizagem histórica comprometida com a emancipação dos sujeitos, desafiando as formas tradicionais de aprendizagem, conforme diz a autora:

Seja em função da manutenção ou da mudança de uma determinada concepção de mundo, mostra-se como fundamental a necessidade de modificar, de maneira duradoura e concreta, os modos de internalização do conhecimento historicamente existentes, desafiando as formas atualmente dominantes de cognição, consolidadas em favor do capital. (SCHMIDT, 2009, p.35)

Para Rüsen (2010): 
a formação da consciência histórica não é, por conseguinte, poder dispor de saberes, mas de formas de saber, de princípios cognitivos que determinam a aplicação dos saberes aos problemas de orientação. Naturalmente essas competências dependem dos conteúdos do saber. Elas não podem estar vazias da experiência do tempo passado, elaborada e interpretada cognitivamente, uma questão de competência cognitiva na perspectiva temporal da vida prática, da relação de cada sujeito consigo mesmo e do contexto comunicativo com os demais. (RÜSEN, 2010 d, p.101)

\section{A pesquisa autoetnográfica e a educação histórica}

Pensando as características locais, a diversidade de sujeitos em sala de aula, as relações que a escola estabelece nesse espaço e principalmente o percurso formativo desses alunos no ensino fundamental, é que se pensou a metodologia de sala de aula. Essas informações foram sendo apontadas no Diário de Campo desde o inicio do ano de 2014, quando se definiu esse espaço como campo empírico, o que não impediu que trouxesse apontamentos e observações de algumas questões relevantes do cotidiano da escola, a forma de trabalhar da professora de ensino fundamental e o uso intensivo do livro didático são algumas delas. Segundo Santos (2011, p. 3) o livro didático deve ser um instrumento auxiliar do professor, para que dessa forma ele busque "caminhos possíveis para sua prática pedagógica, servindo de orientação para que tenha autonomia na utilização de várias fontes e experiências para complementar seu trabalho em sala de aula", mas essa é uma realidade distante do que observei. Portanto, concordo com autora onde afirma:

O estudo da relação entre o conceito de passado que possui o professor e as ideias de passado presentes no livro didático escolhido e utilizado por ele, pode mostrar o que é considerado válido e significante e qual a ideia de cultura que acredita estar transmitindo. (SANTOS, 2011, p.3)

Considerando esses aspectos as abordagens iniciais com a turma deram-se de forma muito mais dialógica do que propriamente em forma de "aula de História", pois precisava sentir, reconhecer de que forma eles identificam a disciplina, se gostam, se não, e o que se lembravam do nível anterior. Para isso as fases iniciais se deram em forma de sondagem, aos moldes de Lourençato 
(2012), que desenvolveu uma abordagem exploratória para trabalhar com alunos do terceiro ano de ensino médio de duas escolas da cidade de Londrina - PR. Utilizando um formulário com dez perguntas abertas ela traçou um perfil inicial dos jovens alunos, um reconhecimento do seu campo empírico. Busquei nesse estudo exploratório da autora a base inicial para a criação de um formulário para ser utilizado com os alunos dessa pesquisa. O que chamo de sondagem inicial trouxe além do caráter da identificação, algumas perguntas sobre seu cotidiano de estudo como aluno, acesso e uso da internet e alguns conceitos substantivos iniciais, para que eu pudesse ter uma primeira impressão sobre suas ideias históricas.

Após essa primeira abordagem, as duas ou três semanas seguintes, considerando que a disciplina possui apenas uma hora semanal, seriam para trabalhar conforme o plano de estudos da escola, a "Introdução a História" e os "conceitos de Historiografia" ou o que é a historiografia, para ficar mais coerente. Nessa perspectiva a sequência do trabalho se daria na instrumentalização da Aula Oficina (BARCA, 2004) desenvolvendo uma unidade temática investigativa para a aprendizagem histórica, conforme Lindamir Zeglin Fernandes (2007)

A análise do primeiro instrumento de sondagem fez com que esse percurso fosse reprogramado. Não encontrando coerência nas respostas, e um desprezo pela disciplina por parte de alguns alunos, vi a necessidade de compreender como esses alunos sentem-se, como sujeitos históricos, se eles se reconhecem em sua própria história. Utilizando a experiência "intuitiva" de Luciano de Azambuja (2010) que para tomar conhecimento de seus alunos do 20 ano do ensino médio de uma escola técnica, desenvolveu uma atividade chamada Projeto Histórias de Vidas, uma atividade autobiográfica na qual ele se apresentou aos alunos narrado a sua história de vida, depois pediu que os alunos realizassem suas autobiografias a partir de um roteiro pré-estabelecido. Ao preparar o roteiro autobiográfico considerei importante realizar algumas alterações ao original de Azambuja (2010), pois precisava perceber algumas peculiaridades da turma além das abordadas pelo autor, tais como: ascendência étnica, religiosidade, fatos marcantes de suas vidas, o que gostam de fazer quando não estão na escola, trabalhando ou realizando suas atividades junto à família, e seus projetos para o futuro. 
A partir dessas observações, a necessidade de mudança no foco conceitual inicial de aprendizado foi estabelecida. Notadamente a religiosidade local e da professora de ensino fundamental, somadas a sua carência metodológica (apontamentos em Diário de Campo GT das Ciências Humanas dia 13/05/2014), contribuíram para que os alunos não construíssem um conhecimento inicial sobre o desenvolvimento e as primeiras formas de socialização humana, fato que ocorre também nas disciplinas de Ciências no ensino fundamental e Biologia no ensino médio quando o assunto é evolução das espécies. Para Santos (2013, p. 158).

\begin{abstract}
Enquanto sujeitos do universo escolar, os professores trazem consigo diferentes experiências e expectativas que podem ser percebidas em suas práticas e nas suas escolhas educativas. Neste sentido, é na escola que ocorre a experiência social por excelência, onde o indivíduo toma consciência da sua relação com a sociedade e com a realidade. Uma das principais funções ou finalidades da escola está também na compreensão dos sujeitos que dela fazem parte: corpos docente e discente, direção, pais, entre outros sujeitos pertencentes a esse cotidiano. [...] A atividade do docente se concretiza em um conjunto de pensamentos que constroem um modo particular de interpretação da realidade.
\end{abstract}

Tomando como ponto de partida a evolução humana, e com a ideia de resignificar crenças, valores e representações foi pensado a utilização do filme em sala de aula. Marcando a premissa de Marcos Napolitano (2010) que o filme deve conectar o aluno ao mundo da escrita, e que em momento algum deve ser visto como substituição da leitura. Levantam-se as hipóteses, de que forma eles reconhecem o desenvolvimento humano, para depois contextualizar o filme, como uma obra cinematográfica que busca mostrar fatos comprovados cientificamente através da estética das imagens. Nas palavras do autor "mesmo o filme sendo uma ficção, quando o adulto, aluno ou professor vai ver, sempre há um pacto de realidade naquelas duas ou mais 'horinhas' dentro da sala escura". O cinema na História ocupa um "estatuto intermediário" entre visões "objetivistas" e "subjetivistas", segundo Napolitano (2008, p. 236):

Seu caráter ficcional e sua linguagem explicitamente artística, por um lado, Ihe conferem uma identidade de documento estético, portanto, a primeira vista, subjetivo. Sua natureza técnica, sua 
capacidade de registrar e, hoje em dia, de criar realidades objetivas, encenadas num outro tempo e espaço, remetem por outro lado, a certo fetiche da objetividade e realismo, reiterado no pacto que os espectadores efetuam quando entram numa sala de cinema ou ligam o aparelho de televisão. A força das imagens, mesmo quando puramente ficcionais, tem a capacidade de criar uma "realidade" em si mesma, ainda que limitada ao mundo da ficção, da fábula encenada e filmada. [...] Em outras palavras, é menos importante saber se tal ou qual filme foi fiel aos diálogos, à caracterização física dos personagens ou a reprodução de costumes e vestimentas de um determinado século. O mais importante é entender o porquê das adaptações, omissões, falsificações que estão apresentadas num filme.

A o pensar a temática a ser abordada tratando da evolução do homem em sociedade, o título escolhido foi "A Guerra do Fogo" (1981). O filme é uma produção conjunta entre Canadá, França e EUA, sob a direção de Jean-Jacques Annaud, mostra com uma estética bem estudada e uma linguagem desenvolvida propriamente para dar o máximo de realidade a um contexto Pré-Histórico de desenvolvimento das sociedades humanas. A análise do filme trouxe aos alunos o que a religião não admite uma evolução além de social, biológica do homem, mostrando também que essa evolução não foi linear, apontando assim vários aspectos que os alunos não tiveram contato em sua formação de ensino fundamental.

Roger Chartier (2010, p. 24) diz:

Entre história e ficção, a distinção parece clara e resolvida se se aceita que, em todas suas formas (míticas, literárias ou metafóricas), a ficção é "um discurso que 'informa' do real, mas não pretende representá-lo nem abandonar-se nele", enquanto a história pretende dar uma representação adequada da realidade que foi e já não é. Nesse sentido, o real é ao mesmo tempo o objeto e o fiador do discurso da história.

O incomodo causado para aqueles que têm uma convicção fervorosa na religiosidade foi perceptível pelos comentários gerados durante a exibição do filme. Interrompemos por várias vezes para dialogar a respeito do ponto de vista que eles trazem como a estética, as imagens, onde a intensão do autor mexeu com eles. A partir do filme eles criaram uma narrativa que abordasse os seguintes aspectos: a compreensão que eles tiveram do filme, como eles enxergam essa "evolução humana" apresentada, como eles aprenderam sobre a 
criação humana, para eles o que poderia ter sido, ou foi diferente do apresentado no filme? A primeira leitura realizada das narrativas confirmou as observações a respeito da aprendizagem construída no ensino fundamental e a força da religiosidade na turma, ao ponto de ter trechos nas narrativas que desacreditam totalmente da ciência "Deus criou o homem assim já, nunca tivemos pelos, nem somos irmãos dos macacos" (nota de Diário de Campo de 24/03/14).

O trabalho com jovens nesse contexto por vezes é incerto e entender a subjetividade desses sujeitos é tão complexo quanto compreender suas atitudes em grupo. Depois de ler o que eles escreveram sobre o filme, pensei em buscar entender como eles se compreendem nesse meio, onde, na escola, eles constroem um tipo de conhecimento, e nas comunidades evangélicas eles têm uma doutrina muito conservadora, mas nas conversas na escola eles têm um comportamento que não fecha com essa doutrina, com raras exceções.

A cidade é extremamente pequena, são 3. 935 habitantes conforme censo IBGE 2010, e as opções para eles são limitadas, para não dizer que quase não existem. Pensei em uma abordagem "musical" (AZAMBUJA 2010) para falar em juventude, valores, liberdade, direitos, deveres (que foi tema também da palestra que eles haviam assistido semanas antes). Com a música "Tempo Perdido" de Renato Russo (1986), eu trouxe o contexto em que ele compôs a letra, e pedi que eles pensassem esse "conceito" de juventude a partir do que eles vivem: família, Igreja, escola, conhecimento, internet, valores, direitos, deveres e liberdades, e pensando no futuro que eles querem ter. Um trabalho lento e delicado ao considerarmos que eles estão em uma faixa etária que para muitos é uma "passagem" como coloca Juarez Dayrell

[...] nos deparamos no cotidiano com uma série de imagens a respeito da juventude que interferem na nossa maneira de compreender os jovens. Uma das mais arraigadas é a juventude vista na sua condição de transitoriedade, na qual o jovem é um "vir a ser", tendo no futuro uma passagem para a vida adulta, o sentido das suas ações do presente. Sob essa perspectiva, há uma tendência de encarar a juventude na sua negatividade, o que ainda não chegou a ser (Salem, 1986), negando o presente vivido. (DAYRELL, 2003, p.40)

Tomo esse "período" da vida desses personagens, não como uma "passagem para a vida adulta", mas que nessa transitoriedade, suas identidades 
são construídas e colocadas à prova dentro do contexto onde eles se relacionam. Essa reflexão serviu também para que eles pensassem sobre suas atuações na sociedade local. Como jovens historicamente constituídos, que logo estarão exercendo papeis "da vida adulta". Schmidt (2009, p. 35) coloca a função didática de formar a consciência histórica como a de fornecer elementos de orientação e interpretação "para dentro, construindo identidades, e, para fora, fornecendo sentidos para ação da vida prática". Ainda na conceituação da autora:

\begin{abstract}
Nesse sentido, os princípios orientadores de uma contraconsciência histórica devem ser absolutamente desatados da lógica do capital e da imposição da conformidade, incorporando, também, o pressuposto inegociável de que qualquer aprendizagem é autoeducação e inseparável da prática significativa da autogestão, em que os jovens e crianças sejam agentes ativos de sua própria educação. Para isto, é preciso também que se pensem as crianças e os jovens como categorias historicamente construídas, determinadas socialmente e culturalmente, o que aponta a importante relação entre escolarização, condição infantil e condição juvenil. Isto é, crianças e jovens são sujeitos no "universo escolar" e as relações que se estabelecem com o conhecimento devem ser pensadas a partir desses pressupostos. (SCHMIDT, 2009, p. 36)
\end{abstract}

Dessa maneira, com material suficiente para poder ter uma compreensão inicial de quem são meus sujeitos, retomei o percurso investigativo pensado, com a abordagem através da unidade temática investigativa (FERNANDES, 2007, p. 6).

[...]primeira ênfase foi a escolha da temática direcionada pela diretriz curricular e planejamento do professor. [...]segunda ênfase: a elaboração de perguntas para investigar os conhecimentos prévios a partir dos objetivos de ensino planejados para a temática. [...] terceira ênfase: depois da categorização e análise pelo professor das respostas dos alunos para os conhecimentos prévios, a problematização junto aos alunos. [...] a quarta ênfase: comunicação como processo mais formal de avaliação. [...] Na quinta ênfase: perguntas para captar a verbalização do aluno quanto à consciência histórica.

Tomando como conceitos iniciais: agricultura, civilização, urbanização e relações de trabalho, venho desenvolvendo as atividades iniciais dentro da 
proposta de Fernandes. Partindo dos princípios da cognição histórica situada, experiência, orientação e interpretação, onde esses "princípios cognitivos" movimentam recursos ou materiais chamados conceitos históricos e categorias históricas, pelos quais são construídas as teorias históricas. Para Schmidt (2009, p. 37):

[...] aprender História significa contar a História, isto é, significa narrar o passado a partir da vida no presente. O principal objetivo é elaborar uma orientação relacionada com a construção da identidade de cada um e, também, organizar a própria atuação nas lutas e ações do presente, individual e coletivamente.

Para Rüsen (2010, p. 43) "o aprendizado histórico pode ser compreendido como um processo mental de construção de sentido sobre a experiência do tempo através da narrativa histórica, na qual as competências para tal narrativa surgem e se desenvolvem". Essas narrativas, desde a primeira realizada, são analisadas e categorizadas para que se possa acompanhar o desenvolvimento da compreensão, do aprendizado e da consciência histórica. Essa categorização baseia-se na tipologia desenvolvida por Rüsen (2010) onde o processo que pode não ocorrer de forma linear, mas conter uma dualidade em seu interior, que são marcas de seus conceitos pré-concebidos. Assim em uma mesma narrativa podemos encontrar uma ou mais das tipologias desenvolvidas por Rüsen (2010), as narrativas de tipo tradicional, exemplar, crítica ou genética, trazem consigo a afirmação, negação, regularidade ou transformação em relação à orientação temporal, cultural, política ou social. O autor afirma que a narrativa é vista como aprendizado "quando com ela, as competências forem adquiridas através de uma função produtiva do sujeito, com as quais a História será apontada como fator de orientação cultural da vida prática humana" (ibid., p. 43).

Do ponto de vista da cognição histórica situada, a explicação histórica constitui parte fundamental na narrativa histórica, processo inerente à natureza do próprio conhecimento histórico. Assim, a cognição histórica situada assume como pressuposto da aprendizagem a própria natureza narrativística da ciência da História. (SCHMIDT, 2009, p. 43) 
O percurso metodológico em sala de aula ainda está em andamento, as análises das narrativas dos alunos estão sendo realizadas e cruzadas com dados dos instrumentos iniciais, a sondagem e a autobiografia. Assim repenso cada passo a ser dado dentro dessa investigação, porém a analise das narrativas tem o objetivo teórico que é o de identificar o desenvolvimento da consciência histórica desses jovens, para isso busco em Jörn Rüsen, Maria Auxiliadora Schmidt, Isabel Barca, Peter Lee entre outros desse referencial a base epistemológica da aprendizagem histórica. Que compreendem a aprendizagem histórica na seguinte forma:

[...] espera-se que o aparato conceitual da história habilite os jovens a desenvolverem de forma objetiva, fundamentada porque assente na análise crítica da evidência, as suas interpretações do mundo humano e social, permitindo-lhes, assim, melhor se situarem no seu tempo. A consciência histórica será algo que ocorre quando a informação inerte, progressivamente interiorizada, torna-se parte da ferramenta mental do sujeito e é utilizada, com alguma consistência, como orientação no quotidiano. (SCHMIDT et al, 2010, p. 16)

As interpretações e a categorização das narrativas e cruzamento com as observações de nível social proporcionam o entendimento de como os sujeitos se posicionam frente à vida. E de que maneira podem ou não refletir sobre seu futuro e através da aprendizagem histórica desenvolver sua consciência histórica. Mexer com lembranças que eles mal construíram em suas aprendizagens anteriores, revolver lembranças minhas, que trazem influências na minha forma de ensinar.

A narrativa constitui (especificamente) a consciência histórica na medida em que recorre a lembranças para interpretar as experiências do tempo. A lembrança é, para a constituição da consciência histórica, por conseguinte, a relação determinante com a experiência do tempo. [...] Não se deve entender tudo isso, todavia, como se a constituição da consciência histórica pela narrativa histórica se limitasse à recuperação do passado pela lembrança. [...] Não há outra forma de pensar a consciência histórica, pois ela é o local em que o passado é levado a falar - o passado só vem a falar quando questionado; e a questão que o faz falar origina-se da carência de orientação da vida prática atual diante de suas virulentas experiências de tempo. (RÜSEN, 2010, p. 62/63) 
As minhas reações, indagações e reflexões sobre a minha prática, minha identidade como professora de História, também estão colocadas explicitamente, pois levanto questionamentos que expõe minhas emoções frente aos fatos que se apresentam e que vivencio. Dessa forma concordo com Scribano e De Sena (2009) quando falam que o investigador é parte da cultura que investiga, está socializado a ela e põe em jogo elementos pessoais e sociais, tem que dar conta do que escuta, sente, da temática a ser pesquisada e refletir a própria experiência, "el investigador 'es arte y parte'".

\section{A guisa de uma conclusão parcial}

Refiro-me a conclusão parcial, pois minha atividade encontra-se em andamento. O que trago nesse texto é no sentido de compartilhar uma metodologia que me faz também avaliar a minha consciência histórica. Em que pese que as identidades se permeiam, se desfazem, e recompõe, e como Rüsen (2010, p. 36) complementa que consciência histórica por ser uma categoria geral não apresenta somente a relação com o aprendizado e o sentido da história, "mas sobre todas as formas de pensamento histórico; através dela se experiencia o passado e se o interpreta como história".

Na perspectiva da autonarrativa, vem também uma autorreflexão, que faz com eu repense o meu aprendizado e que sentido eu dou a História e a minha história. Que consciência histórica tenho desenvolvida, de que maneira eu significo minhas concepções, para que eu possa trabalhar com meus alunos de forma coerente com o estudo que estou desenvolvendo e com as análises teóricas até este momento construídas.

Sribano e De Sena (2009, p. 6) dizem que ao não existir uma "receita certa" a metodologia da autoetnografia "es como ir al bosque sin mapa". Para Rusen (2010, p. 62)

[...] o passado é então como uma floresta, para dentro da qual os homens, pela narrativa histórica, lançam seu clamor, afim de compreender ,mediante o que dela ecoa, o que Ihes é presente sob 
forma de experiência do tempo (mais precisamente o que mexe com eles) e poderem esperar e projetar um futuro com sentido.

Parafraseando ambos os autores, busco traçar o mapa do meu bosque, lançando o meu clamor para a floresta do passado, ouvindo seus ecos, procurando, investigando, analisando as experiências para chegar ao meu destino que são aprendizagens e desenvolvimento da consciência histórica.

\section{REFERÊNCIAS:}

AZAMBUJA, L. de. "Fado tropical": protonarrativas de jovens alunos brasileiros e portugueses, escritas a partir das leituras e escutas de uma canção "engajada". $X$ Encontro estadual de História - O Brasil no Sul: cruzando fronteiras entre o regional e o nacional - ANPUHRS, 2010. Disponível em:

http://www.eeh2010.anpuh-

rs.org.br/resources/anais/9/1278260483 ARQUIVO ANPUHTEXTO9.pdf . Último acesso em 26/07/2014.

BRASIL, Instituto Brasileiro de Geografia e Estatísticas - Censo 2010. Disponível em:

http://www.cidades.ibge.gov.br/xtras/perfil.php?lang=\&codmun=431342\&search =rio-grande-do-sul|novo-machado Último acesso em 10/07/2014

CHARTIER, R. A história ou a leitura do tempo. Trad. Cristina Antunes. 2 ed. Belo Horizonte: Autêntica, 2010.

DAYRELL, J. O jovem como sujeio social. Revista Brasileira de Educação. n. 24, Set/Out/Nov/Dez 2003. Disponível em:

http://www.scielo.br/pdf/rbedu/n24/n24a04.pdf Último acesso em 10/07/2014

FERNANDES, L. Z. A reconstrução de aulas de História na perspectiva da Educação Histórica: da aula oficina à unidade temática investigativa. Disponível em: http://www.diaadiaeducacao.pr.gov.br/portals/pde/arquivos/158-4.pdf . último acesso em 26/07/2014.

LOURENÇATO, L. C. A consciência histórica dos jovens-alunos o ensino médio: uma investigação com a metodologia da Educação Histórica. Dissertação de Mestrado em Educação da Universidade Estadual de Londrina - UEL - Londrina, 2012.

MONTERO-SEIBURTH, M. La Auto etnografia como uma Estrategia para la transformación de la Homogeneidad a favor de la Diversidad Individual em la Escuela. Disponível em http://www.uned.es/congreso-inter-educacionintercultural/Grupo discusion 1/74.pdf. Último acesso em 05/07/2014. 
RÜSEN, J. O desenvolvimento da competência narrativa na aprendizagem histórica: uma hipótese ontogenética relativa a consciência moral. In: SCHMIDT, M. A.; BARCA, I.; MARTINS, E. de R. (Org.). Jörn Rüsen e o ensino de História. Curitiba: UFPR, 2010. p. 51-77.

RÜSEN, J. Razão Histórica: teoria da história: os fundamentos da ciência histórica. Trad. Estevão Rezende Martins. Brasília: UNB, 2010.

SANTOS, R. de C. P. dos. A significância do passado para professores de história. Tese apresentada ao Curso de Pós-Graduação em Educação, Setor de Educação, Universidade Federal do Paraná. Curitiba, 2013

Significância histórica, conceito de passado, professores de história e livro didático. Anais Eletrônicos do IX Encontro Nacional dos Pesquisadores do Ensino de História. Florianópolis 2011.

SCHMIDT, M. A. et al. Significados do pensamento de Jörn Rüsen para a investigações na área da educação histórica. In: SCHMIDT, Maria Auxiliadora; BARCA, Isabel; MARTINS, Estevão de Rezende (Org.). Jörn Rüsen e o ensino de História. Curitiba: UFPR, 2010. p. 11 - 21.

SCHMIDT, M. A. Cognição histórica situada: que aprendizagem é esta? Anais XXV Simpósio Nacional de História. Fortaleza, 2009. Disponível em http://anpuh.org/anais/?p=17085

SCHMIDT, M. A.; BARCA, I. (Org.). Aprender História: perspectivas da educação histórica. Ijuí: UNIJUI, 2009.

SCHMIDT, M. A.; BARCA, I.; MARTINS, E. de R. (Org.). Jörn Rüsen e o ensino de História. Curitiba: UFPR, 2010.

SRIBANO, A.; DE SENA, A. Construcción de conocimiento em Latinoamérica: algunas reflexiones desde la auto-etnografía como estratégia de investigación. Cinta Moebio 34: p. 1 - 15. Disponível em http://www.moebio.uchile.cl/34/scribano.html 